Article

\title{
Yield and Characteristics of Pyrolysis Products Obtained from Schizochytrium limacinum under Different Temperature Regimes
}

\author{
Gang $\mathrm{Li}^{1,2}$, Yuguang Zhou ${ }^{2,3, *}$, Fang $\mathrm{Ji}^{2,3}$, Ying Liu ${ }^{2,4}$, Benu Adhikari ${ }^{5}$, Li Tian ${ }^{6}$, \\ Zonghu $\mathrm{Ma}^{6}$ and Renjie Dong ${ }^{2,3}$
}

1 College of Water Resources and Civil Engineering, China Agricultural University, No. 17 Qinghua East Road, Haidian District, Beijing 100083, China; E-Mail: ligangsenior@gmail.com

2 Key Laboratory of Clean Production and Utilization of Renewable Energy, Ministry of Agriculture, P.R. China, No. 17 Qinghua East Road, Haidian District, Beijing 100083, China

3 Biomass Engineering Center/College of Engineering, China Agricultural University, No. 17

Qinghua East Road, Haidian District, Beijing 100083, China; E-Mails: jifang.cau@gmail.com (F.J.); rjdong@cau.edu.cn (R.D.)

4 College of Agriculture and Biotechnology, China Agricultural University, No. 2 Yuanmingyuan West Road, Haidian District, Beijing 100193, China; E-Mail: liuying2012cau@gmail.com

5 School of Health Sciences, University of Ballarat, Mt. Helen, VIC 3353, Australia;

E-Mail: b.adhikari@ballarat.edu.au

6 China Huadian Engineering Co., Ltd., No. 273 Xizhimennei Avenue, Xicheng District, Beijing 100035, China; E-Mails: tianl@chec.com.cn (L.T.); mazh@chec.com.cn (Z.M.)

* Author to whom correspondence should be addressed; E-Mail: zhouyg@cau.edu.cn; Tel.: +86-10-62737858; Fax: +86-10-62737885.

Received: 27 March 2013; in revised form: 14 June 2013 / Accepted: 20 June 2013 / Published: 5 July 2013

\begin{abstract}
Pyrolysis-gas chromatographic mass spectrometry (Py-GC/MS) was used to determine the yield and chemical composition of the pyrolysis products of Schizochytrium limacinum. The pyrolysis was carried out by varying the temperature from $300{ }^{\circ} \mathrm{C}$ to $800{ }^{\circ} \mathrm{C}$. It was found that the main decomposition temperature of Schizochytrium limacinum was $428.16{ }^{\circ} \mathrm{C}$, at which up to $66.5 \%$ of the mass was lost. A further $18.7 \%$ mass loss then occurred in a relatively slow pace until $760.2{ }^{\circ} \mathrm{C}$ due to complete decomposition of the ash content of Schizochytrium limacinum. The pyrolysis of Schizochytrium limacinum at $700{ }^{\circ} \mathrm{C}$ produced the maximum yield $(67.7 \%)$ of pyrolysis products compared to $61.2 \%$ at $400{ }^{\circ} \mathrm{C}$. While pollutants released at $700{ }^{\circ} \mathrm{C}(12.3 \%)$ was much higher than that of $400{ }^{\circ} \mathrm{C}(2.1 \%)$. Higher temperature will lead to more pollutant (nitrogen compounds and PAHs) release,
\end{abstract}


which is harmful to the environment. Considering the reasonably high yield and minimum release of pollutants, a lower pyrolysis temperature $\left(400^{\circ} \mathrm{C}\right)$ was found to be optimum for producing biofuel from Schizochytrium limacinum.

Keywords: Schizochytrium limacinum; microalgae; pyrolysis products; yield; real-time determination

\section{Introduction}

Microalgae cannot be utilized in their natural form as an energy product because this natural biomass requires a certain degree of conversion or modification [1]. However, thermochemical conversion of microalgae can be achieved in relatively short time and carried out with relative ease. For of this reason, it is possible to carry out large-scale production, storage, transportation, distribution and utilization of this natural energy source. Direct combustion, liquefaction, gasification and pyrolysis are some of the most common approaches for thermochemical conversion of biomass [2].

Generally, most of the microalgae is converted into and released as useful energy products during pyrolysis process. As a consequence, products such as pyrolysis gas (composed of $\mathrm{CO}_{2}, \mathrm{H}_{2}, \mathrm{CO}$, and $\mathrm{CH}_{4}$ ), bio-oil (mostly oxygenic organic compounds) and bio-char can be obtained, while pollutants such as nitrogen compounds and polycyclic aromatic hydrocarbons (PAHs) are released during pyrolysis process [3-6]. It is reported that approximately $80 \%$ of the unprocessed biomass can be converted into useful pyrolysis products under optimized reaction circumstances [7]. It is also suggested that many other kinds of energy products can be synthesized using the products obtained from the pyrolysis process $[8,9]$.

Earlier investigations have shown that the ecological environment prevailing during the cultivation of microalgae greatly affects the process of concentration of important elements of the microalgae [10]. Bio-oil and soluble polysaccharides are major constituents of microalgae, while pigments and vitamins, etc. are minor constituents [11]. The mechanisms involved in generation and modification of pyrolysis products from microalgae are still poorly understood. Hu et al. [12] reported that when Chlorella vulgaris was pyrolyzed by microwave treatment, $35.8 \%$ of bio-oil was obtained at $1500 \mathrm{~W}$ microwave power. These authors also achieved a gas yield of $52.4 \%$ at $2250 \mathrm{~W}$ microwave power.

Gaseous products obtained after pyrolysis of biomass can be analyzed by means of thermogravimetric analysis-Fourier transform infrared spectroscopy (TGA-FTIR), which provides a real-time weight (mass) loss data [13-16]. Both soluble organic compounds in liquid and solid pyrolysis products can be conveniently determined by high performance liquid chromatography (HPLC) or gas chromatography (GC). By collecting a number of products over different stages of pyrolysis, retention times and the peak area percentages characteristic to each product can be automatically calculated and recorded by GC-MS [17-20]. Further data or profiles such as the absolute intensity and concentration level can also be automatically calculated by integration and by comparing against standard material databases, such as the NIST (National Institute of Standards and Technology) library.

Pyrolysis-gas chromatography-mass spectrometer (Py-GC/MS) is one of the most effective means for the characterization of complicated compounds obtained during the pyrolysis process. 
Thangalazhy-Gopakumar et al. [21] investigated catalytic pyrolysis of pine wood using $\mathrm{H}^{+} \mathrm{ZSM}-5$ in hydrogen-rich environment by Py-GC/MS; Greenhalf et al. [6], used Py-GC/MS to characterize and compare fast pyrolysis product yield from straw, high yielding perennial grasses and hardwoods; $\mathrm{Du}$ et al. [4] carried out catalytic pyrolysis of three major components (carbohydrates, proteins, and lipids) via Py-GC/MS to better understand the pyrolysis of microalgae. Py-GC/MS also could provide highly efficient sample injection [22-25]. In most cases, several micrograms of samples can be instantly pyrolyzed between $400{ }^{\circ} \mathrm{C}$ and $900{ }^{\circ} \mathrm{C}$. A number of spectra of pyrolysis products can be obtained since their volatility decreases with the increase in the molecular weight. Therefore, the investigation on pyrolysis process of microalgae is of utmost importance, especially when greater understanding of the first-order and the second-order pyrolysis processes is required.

In this study, we aimed at determining the yield and chemical composition of pyrolysis products obtained from Schizochytrium limacinum using Py-GC/MS over a broad pyrolysis temperature range of $300 \sim 800{ }^{\circ} \mathrm{C}$. It was expected that it could provide an optimum pyrolysis temperature, at which an optimum yield of pyrolysis product obtained at considerably low risk of releasing harmful pollutants.

\section{Results and Discussion}

\subsection{Composition Analysis}

The moisture content (dry basis) of dried Schizochytrium limacinum samples used for elemental analysis was 3.18\%. Major elemental contents including carbon, hydrogen, and nitrogen were found to be $59.61 \%, 8.135 \%$, and $2.295 \%$, respectively. The carbon content of Schizochytrium limacinum was slightly higher than that of Undaria pinnatifida (56.5\%); however, lower than the carbon contents of Laminaria japonica (73.5\%) and Porphyra tenera (65.7\%) [26]. The elemental composition of high carbon content and relatively low nitrogen content suggests that this particular microalgae has great potential in energy production.

\subsection{Differential Scanning Calorimetry}

The DSC thermogram of Schizochytrium limacinum is presented in Figure 1. As can be seen from this figure, multiple endothermic processes are observed when this microalgae is heated. The presence of these multiple endothermic peaks can be attributed to the heterogeneity in composition, in other words, Schizochytrium limacinum samples are multi-component systems [27]. The physical transition phenomena such as glass transition, ice fusion, protein denaturation, lipid melting, and decomposition can also be observed in this thermogram (Figure 1). It showed a small step-change in heat flow from $-37.94{ }^{\circ} \mathrm{C}$ to $-30.91{ }^{\circ} \mathrm{C}$ which is indication of glass transition occurring in the sample with an enthalpy change of $0.4034 \mathrm{~J} / \mathrm{g}$. Two endothermic peaks also appeared within a temperature range of $39.91{ }^{\circ} \mathrm{C}$ to $50.85^{\circ} \mathrm{C}$ and at $79.78{ }^{\circ} \mathrm{C}$ which can be attributed to thermal denaturation of protein. The endothermic peak at $139.52{ }^{\circ} \mathrm{C}$ could be considered as melting of lipid content [26]. An exothermic peak was detected around $285^{\circ} \mathrm{C}$ which was probably due to the partial decomposition of the sample. 
Figure 1. The thermogram of Schizochytrium limacinum obtained from DSC showing multiple endothermic transitions.

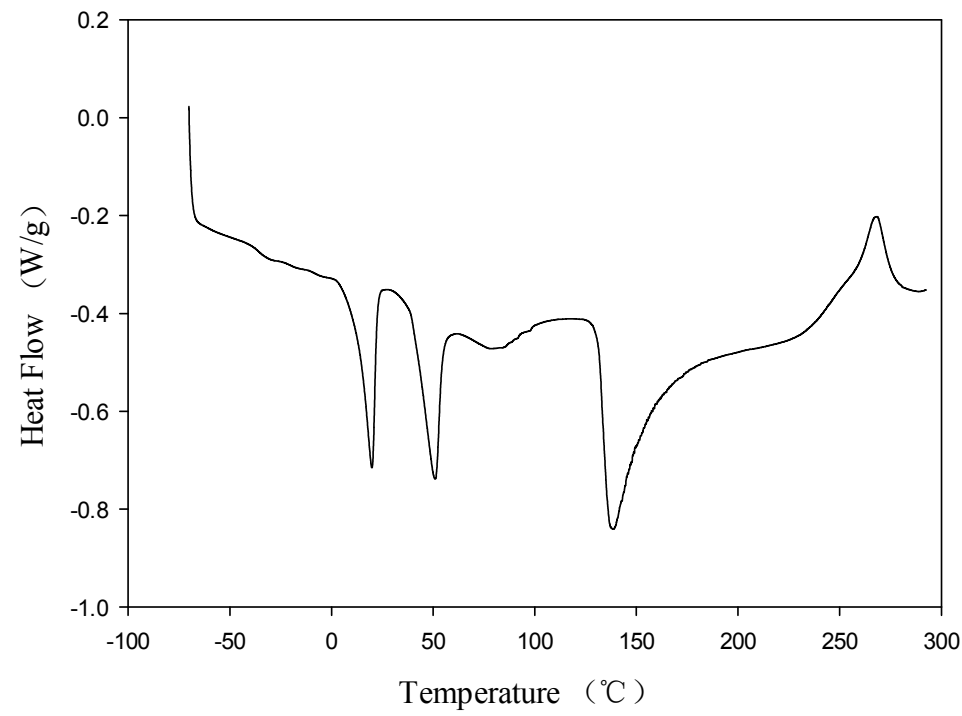

\subsection{Thermogravimetric Analysis}

As can be seen from Figure 2, the sample weight started to decrease at $70.88^{\circ} \mathrm{C}$ (onset temperature) and a significant decrease occurred at $285.17{ }^{\circ} \mathrm{C}$. Most of the decomposition of carbohydrates and proteins occurred from $300{ }^{\circ} \mathrm{C}$ until $500{ }^{\circ} \mathrm{C}$ which resulted into $65.5 \%$ of weight loss [28] (Figure 2).

Figure 2. Thermogravimetric analysis of Schizochytrium limacinum.

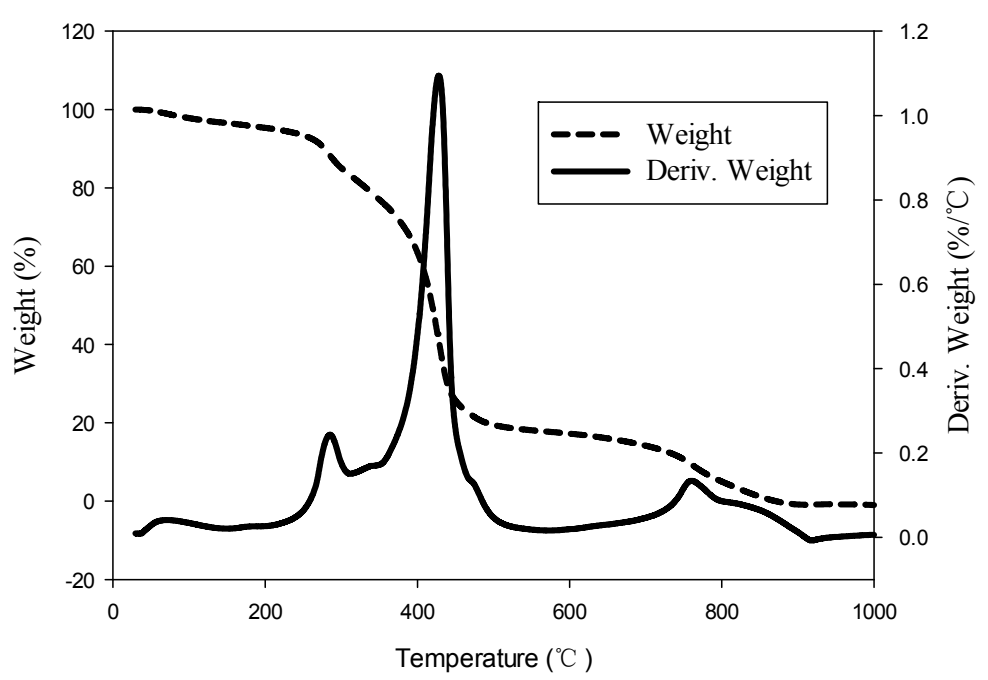

As can be seen from the derivative weight loss curve, $428.16{ }^{\circ} \mathrm{C}$ can be taken as the main decomposition temperature. Figure 2 (weight loss curve) shows that another $18.7 \%$ weight loss occurred at $760.17{ }^{\circ} \mathrm{C}$, which suggests that a complete decomposition of ash content and proceeds relatively slowly [26]. It can also be seen from Figure 2 that a temperature range of $40{ }^{\circ} \mathrm{C}$ to $800{ }^{\circ} \mathrm{C}$ covers the entire decomposition range of Schizochytrium limacinum and suggests that the highest pyrolysis temperature $\left(800^{\circ} \mathrm{C}\right)$ chosen in Py-GC-MS experiments in current study is adequate. 


\subsection{Pyrolysis Products of Schizochytrium Limacinum by GC/MS}

In previous studies the pyrolysis products of biomass were collected after treatment and the GC-MS experiments were then subsequently performed on these collected products. In this study, the pyrolysis products of Schizochytrium limacinum at varying degradation levels and subjected to different temperatures were detected in real-time using Py-GC-MS. The total ion current (TIC) diagram obtained at $450{ }^{\circ} \mathrm{C}$ is presented in Figure 3 and the retention time and percentage of peak areas are presented in Table 1.

The chemical compounds identified by GC-MS were classified into several groups such as aliphatics (including alkanes, and alkenes), aromatics (e.g., benzene, benzene alkyl derivatives, indenes, and fluorenes), acids, nitrogen compounds (e.g., amides, nitriles, indoles, and pyridines), phenols, furans, polycyclic aromatic hydrocarbons (PAHs), and alcohols and presented in Table 2. The identified compounds and their relative peak areas were found to be similar to those reported earlier by Thangalazhy-Gopakumar et al. [29]. The relative areas of each compound group at different pyrolysis temperatures are presented in Table 2.

Among the compounds listed in Tables 1 and 2, aliphatic hydrocarbons exist naturally in fossil oil and they are valuable components in bio-oil for fuel application [3,21]. As temperature is increased, different aliphatic hydrocarbon compounds are released at different temperatures. As shown in Table 2, the relative amount of aliphatic hydrocarbons in pyrolysis products of Schizochytrium limacinum has increased as the temperature increased from $300{ }^{\circ} \mathrm{C}$ to $700{ }^{\circ} \mathrm{C}$. The aliphatic hydrocarbon content increased to its highest value $(19.6 \%)$ at $700{ }^{\circ} \mathrm{C}$. This maximum aliphatic hydrocarbon value found in this study was higher than those reported in earlier studies [3,30]. In addition, the maximum aliphatic hydrocarbon content found in this study was much higher than the maximum hydrocarbon content in pyrolysis products obtained from other types of biomass [31-33]. This might be due to the fact that higher amounts of lipids in Schizochytrium limacinum are converted into aliphatic hydrocarbons during pyrolysis [21]. At higher temperatures, aliphatic hydrocarbons are produced from the decarboxylation reaction of fatty acids accompanied with the release of carbon dioxide. Similarly, medium- and long-chain aliphatic hydrocarbons are cracked into short-chain ones with increasing temperature [3,21].Table 2 further shows that the aliphatic hydrocarbon content decreased with the increase in the temperature above $700{ }^{\circ} \mathrm{C}$. The release of aliphatic hydrocarbon content was second highest $(16.9 \%)$ at $800{ }^{\circ} \mathrm{C}$. These observations agree with the earlier reports that relatively higher amount of aliphatic hydrocarbons are obtained in pyrolysis products at elevated temperatures $\left(500 \sim 800{ }^{\circ} \mathrm{C}\right)$ than at temperatures between $300{ }^{\circ} \mathrm{C}$ and $400{ }^{\circ} \mathrm{C}$ [3]. Our finding that the relative content of aliphatic hydrocarbons did not strongly depend on temperature when the temperature was varied between $500{ }^{\circ} \mathrm{C}$ and $700{ }^{\circ} \mathrm{C}$ is in accordance with an earlier report [3]. Aromatic hydrocarbons serve as important industrial chemicals and transportation fuel additives to increase octane number. As can be seen from Table 2, the relative content of aromatic hydrocarbons in pyrolysis products of Schizochytrium limacinum increased with as the temperature increased from $300{ }^{\circ} \mathrm{C}$ to $800{ }^{\circ} \mathrm{C}$. The aromatic hydrocarbon content reached the highest value of $41.1 \%$ at $800^{\circ} \mathrm{C}$, which is also higher than the value reported in literature [30]. This observation suggests that benzene and benzene derivatives are major aromatic compounds in Schizochytrium limacinum. The data presented in Table 1 and Table 2 also suggest that more aromatic compounds such as indenes and 
fluorenes are present in pyrolysis products of Schizochytrium limacinum in addition to benzene and its derivatives. The presence or absence of indenes and fluorenes is expected to depend on the species, chemical composition and the temperature used during pyrolysis.

According to Li et al. [3], the fatty acids in the pyrolysis products are mainly produced from the pyrolysis of lipids. We have identified these fatty acids to be the long-chain $\left(\mathrm{C}_{14} \sim \mathrm{C}_{18}\right)$ compounds in this paper in contrast to the short chain acid (acetic acid) reported by Li et al. Furthermore, the relative content of acid in pyrolysis products of Schizochytrium limacinum firstly increased with the increase in temperature from $300{ }^{\circ} \mathrm{C}$ to $400{ }^{\circ} \mathrm{C}$ and reached its highest value $(59.5 \%)$. The fatty acid content subsequently decreased with increasing temperature above $500{ }^{\circ} \mathrm{C}$. Those results indicate that the lower pyrolysis temperatures are more beneficial for generation of fatty acids, which agrees with the previous report [3].

The presence of nitrogen compounds in the pyrolysis products is assumed to be due to degradation of proteins and they account for the potential emission of nitrogen oxides during fuel combustion [3,29,34]. The relative content of nitrogen compounds in pyrolysis products of Schizochytrium limacinum increased as the temperature was increased from $300{ }^{\circ} \mathrm{C}$ to $800{ }^{\circ} \mathrm{C}$. The concentration of nitrogen products reach a highest value $(6.7 \%)$ which is in accordance with the data reported by Li et al. However, the maximum concentration of nitrogen compounds was found to be lower than those reported by Li et al. [3] and Du et al. [30].

The presence of phenols and phenolic compounds is important in pyrolysis products if they can be produced commercially from Schizochytrium limacinum. As can be seen from Table 2, the maximum concentration of phenols and phenol derivatives is $6.7 \%$ at $300{ }^{\circ} \mathrm{C}$. It can also be seen from Table 2 that the relative contents of phenols and phenol derivatives has decreased when the temperature increased from $300{ }^{\circ} \mathrm{C}$ to $500{ }^{\circ} \mathrm{C}$. The concentration of phenol and phenol derivatives decreased down to 0 when the temperature increased above $600{ }^{\circ} \mathrm{C}$. The maximum phenols and phenol derivatives value observed in this study was slightly higher than the corresponding value reported by $\mathrm{Du}$ et al. [30] (6.2\%). The maximum phenols and phenol derivate contents in Schizochytrium limacinum were almost identical in pyrolysis products obtained from brown algae (Macrocystis pyrifera) at $500{ }^{\circ} \mathrm{C}[28]$.

As typical pollutants, polycyclic aromatic hydrocarbons (PAHs) not only exist in fossil fuels, but also can be produced from fuel combustion and pyrolysis. Table 2 shows that PAHs are not detected until $500{ }^{\circ} \mathrm{C}$. The concentration of the PAHs at $500{ }^{\circ} \mathrm{C}$ was $0.9 \%$. However, the concentration of the PAHs increased when the temperature further increase above $600{ }^{\circ} \mathrm{C}$. The concentration of the PAHs was the highest $(9.05 \%)$ at $800{ }^{\circ} \mathrm{C}$. Those results are in accordance with the data reported earlier by $\mathrm{Li}$ et al. and confirm the fact that the formation of PAHs is greatly increased at high temperatures. There are three possible pathways through which the PAHs are formed: Diels-Alder reactions, deoxygenation of oxygenated aromatic compounds and pyrolysis of proteins [3].

Alcohols were not detected in the pyrolysis products of Schizochytrium limacinum up to $400{ }^{\circ} \mathrm{C}$ (Table 2). The alcohols are detected when the temperature was increased from $400{ }^{\circ} \mathrm{C}$ to $500{ }^{\circ} \mathrm{C}$ and their concentration reached the highest value $(5.1 \%)$ at $600{ }^{\circ} \mathrm{C}$. The alcohol content also started decrease when the temperature was above $700{ }^{\circ} \mathrm{C}$. 
The relative content of furans in pyrolysis products of Schizochytrium limacinum increased to its highest value $(0.5 \%)$ at $300{ }^{\circ} \mathrm{C}$ (Table 2). Above this temperature the concentration of furans decreased continuously.

Li et al. [3] also pyrolyzed other types of biomass materials for bio-oil production. Their results indicated that pyrolysis products of pine sawdust comprised acids, sugars, phenols, carbonyls and alcohols, etc. Compared to the results in current research, the pyrolysis products showed apparent differences. The bio-oil from algal biomass was characterized by higher contents of hydrocarbons, acids, and nitrogenous compounds, but lower contents of phenols, alcohols, and furans than that of pine sawdust at the same pyrolysis temperature.

Table 1. Retention time and the percentage of peak areas of the pyrolysis products obtained from Schizochytrium limacinum at $450^{\circ} \mathrm{C}$.

\begin{tabular}{ccc}
\hline Compounds & Peak area percentage (\%) & Retention time (min) \\
\hline Hexadecanoic acid & 33.8309 & 25.7676 \\
Tetradecanoic acid & 9.476 & 21.6705 \\
Pentadecane & 5.747 & 18.0548 \\
Octadecanoic acid & 2.2188 & 27.9498 \\
Cyclotetradecane & 2.1607 & 16.6428 \\
1,4-Cyclohexadiene & 1.754 & 4.3944 \\
1,2-Benzenediol & 1.3867 & 14.6638 \\
1,3,5-Cycloheptatriene & 1.3613 & 5.6834 \\
Tetradecane & 1.2571 & 15.3805 \\
1-Butyl-2-ethylcyclobutane & 0.8392 & 13.7973 \\
9,12-Octadecadienoic acid (Z,Z)- & 0.7804 & 27.6503 \\
Hexadecanoic acid, 4-nitrophenyl ester & 0.7181 & 26.9229 \\
1-Ethenyl-4-ethylbenzene & 0.7124 & 12.8399 \\
Tetradecane & 0.6026 & 16.7284 \\
Butylbenzene & 0.4052 & 11.6686 \\
2,4,6-Tris(1-methylethyl)phenol & 0.2806 & 18.3062 \\
Indole & 0.236 & 15.5945 \\
Benzenepropanoic acid & 0.2009 & 16.4182 \\
1-Hexadecanamine & 0.1966 & 28.4312 \\
Pyridine & 0.1858 & 5.3946 \\
Dodecane & 0.1631 & 13.915 \\
3-Furaldehyde & 0.1396 & 6.7532 \\
1-(2-Furanyl)ethanone & 0.111 & 8.9461 \\
(E)-3-Penten-1-yne & 0.0057 & 8.3043 \\
\hline
\end{tabular}


Table 2. Effect of temperature on the pyrolysis products peak area percentage (\%) of Schizochytrium limacinum.

\begin{tabular}{|c|c|c|c|c|c|c|c|}
\hline \multirow{2}{*}{ Groups } & \multirow{2}{*}{ Compounds } & \multicolumn{6}{|c|}{ Schizochytrium limacinum } \\
\hline & & $300^{\circ} \mathrm{C}$ & $400^{\circ} \mathrm{C}$ & $500^{\circ} \mathrm{C}$ & $600^{\circ} \mathrm{C}$ & $700^{\circ} \mathrm{C}$ & $800^{\circ} \mathrm{C}$ \\
\hline \multicolumn{8}{|l|}{ Aliphatics } \\
\hline \multirow{7}{*}{ Alkanes } & 1-Methyl-2-pentyl-cyclopropane & - & - & - & - & 1.75 & 1.48 \\
\hline & cis-1-Butyl-2-methylcyclopropane & - & - & - & 1.81 & 1.67 & 1.47 \\
\hline & Cyclododecane & - & 0.74 & 0.2 & 3.27 & 2.08 & 4.51 \\
\hline & Tridecane & - & - & 0.72 & 0.69 & 0.32 & 0.37 \\
\hline & Tetradecane & - & - & 1.72 & 0.33 & 3.23 & - \\
\hline & Pentadecane & - & 3.17 & 7.04 & 4.84 & 1.46 & 1.22 \\
\hline & Sum & 0 & 3.91 & 9.68 & 10.94 & 10.51 & 9.05 \\
\hline \multirow{14}{*}{ Alkenes } & 1,3-Cyclopentadiene & - & - & 1.63 & 0.79 & 0.028 & 0.12 \\
\hline & 1-Methylcyclohexa-1,3-diene & - & 1.27 & 1.75 & 0.25 & 0.16 & 0.61 \\
\hline & 1-Heptene & - & - & 0.71 & 1.98 & 2.51 & 2.04 \\
\hline & 1,3-Cycloheptadiene & - & - & - & 0.19 & 0.63 & 0.18 \\
\hline & 1,3,5-Cycloheptadiene & - & 0.38 & 1.36 & 0.31 & 0.063 & 0.14 \\
\hline & Bicyclo[4.2.0]octa-1,3,5-triene & - & - & 0.64 & 0.1 & 5.2 & - \\
\hline & 1,3,5,7-Cyclooctatetraene & - & - & - & 0.017 & 0.12 & 7.76 \\
\hline & 1-Decene & - & 0.058 & 3.8 & 3.86 & 2.54 & 2.77 \\
\hline & 1-Undecene & - & - & - & 2.3 & 2.63 & 1.92 \\
\hline & 1-Dodecene & - & - & 1.57 & 2.85 & 2.8 & - \\
\hline & 1-Tridecene & - & - & - & 1.57 & 1.79 & 1.28 \\
\hline & Sum & - & 1.71 & 11.46 & 14.22 & 18.47 & 16.82 \\
\hline & Azulene & - & - & 0.044 & 0.91 & 1.15 & 0.12 \\
\hline & Sum & 0 & 1.71 & 11.50 & 15.13 & 19.62 & 16.94 \\
\hline \multicolumn{8}{|l|}{ Aromatics } \\
\hline \multirow{14}{*}{ Benzenes } & Propylbenzene & - & - & 0.47 & 0.93 & 1.03 & 1.02 \\
\hline & Butylbenzene & - & 0.3 & 0.53 & - & - & - \\
\hline & 1-Butynylbenzene & - & - & - & - & 2.34 & 3.46 \\
\hline & 1,3-Dimethylbenzene & - & - & - & - & 3.22 & 1.91 \\
\hline & 1-Ethenyl-2-Methylbnzene & - & - & - & 0.17 & 2.41 & 0.14 \\
\hline & 1-Ethenyl-4-Methylbenzene & - & - & 0.26 & 1.06 & 1.37 & - \\
\hline & 1-Ethenyl-4-Ethylbenzene, & - & - & - & - & 1.26 & 0.29 \\
\hline & Biphenyl & - & - & - & 0.06 & 0.29 & 0.62 \\
\hline & Toluene & - & - & 2.71 & 5.03 & 8.01 & 11.0 \\
\hline & $p$-Xylene & - & - & - & - & 1.55 & 2.1 \\
\hline & Ethylbenzene & - & 0.62 & 2.7 & 1.89 & 2.67 & 0.31 \\
\hline & Styrene & - & - & 1.76 & 2.11 & 4.32 & 6.87 \\
\hline & Benzocycloheptatriene & - & - & - & - & 1.49 & 2.89 \\
\hline & Sum & 0 & 0.92 & 8.43 & 11.25 & 29.96 & 30.61 \\
\hline \multirow{3}{*}{ Indenes } & Indene & - & - & - & 1.38 & 3.46 & 5.31 \\
\hline & Indan, 1-methyl- & - & - & 0.64 & 0.34 & 0.55 & - \\
\hline & 1H-indene, 1,3-dimethyl- & - & - & - & - & 0.13 & 0.24 \\
\hline
\end{tabular}


Table 2. Cont.

\begin{tabular}{|c|c|c|c|c|c|c|c|}
\hline \multirow{2}{*}{ Groups } & \multirow{2}{*}{ Compounds } & \multicolumn{6}{|c|}{ Schizochytrium limacinum } \\
\hline & & $300^{\circ} \mathrm{C}$ & $400^{\circ} \mathrm{C}$ & $500^{\circ} \mathrm{C}$ & $600^{\circ} \mathrm{C}$ & $700^{\circ} \mathrm{C}$ & $800^{\circ} \mathrm{C}$ \\
\hline \multirow{5}{*}{ Fluorenes } & Fluorine & - & - & - & - & 0.54 & 1.78 \\
\hline & 1-Methyl-9H-fluorene- & - & - & - & - & 0.10 & 0.51 \\
\hline & 4a, 9a-Methano-9H-fluorene & - & - & - & - & 0.20 & 0.031 \\
\hline & Phenanthrene & - & - & - & - & - & 2.64 \\
\hline & Sum & 0 & 0.92 & 9.07 & 12.97 & 34.94 & 41.12 \\
\hline \multirow{5}{*}{ Acids } & Tetradecanoic acid & 3.38 & 9.99 & 5.69 & 8.10 & 6.12 & 0.03 \\
\hline & Hexadecanoic acid & 34.48 & 43.34 & 20.67 & 16.98 & 7.02 & 2.65 \\
\hline & Octadecenoic acid & 1.88 & 3.33 & 1.64 & - & - & - \\
\hline & $(Z, Z)-9,12-O c t a d e c a d i e n o i c ~ a c i d ~$ & 0.055 & 1.89 & 1.51 & 2.58 & - & - \\
\hline & Sum & 39.80 & 58.55 & 29.51 & 27.66 & 13.14 & 2.68 \\
\hline \multicolumn{8}{|l|}{$\begin{array}{l}\text { Nitrogen } \\
\text { compounds }\end{array}$} \\
\hline & Tetradecanamide & - & - & - & 0.68 & 1.27 & 0.66 \\
\hline & Hexadecanamide & 0.30 & 2.10 & 2.40 & 2.18 & 2.08 & 3.02 \\
\hline & Octadecenamide & - & - & - & - & 0.022 & 0.21 \\
\hline & Hexadecanenitrile & - & - & - & 0.51 & 0.46 & 1.69 \\
\hline & Indole & - & - & - & 0.24 & 0.36 & 0.69 \\
\hline & 3-Methyl-1H-indole & - & - & - & - & 0.11 & 0.15 \\
\hline & Pyridine & - & - & 0.27 & 0.074 & 0.19 & 0.30 \\
\hline & Sum & 0.30 & 2.1 & 2.67 & 3.68 & 4.49 & 6.72 \\
\hline \multirow{3}{*}{ Phenols } & Phenol & 1.55 & 1.13 & 0.21 & - & - & - \\
\hline & 1,2-Benzenediol & 13.04 & 1.22 & 1.19 & - & - & - \\
\hline & Sum & 14.59 & 2.35 & 1.4 & 0 & 0 & 0 \\
\hline \multicolumn{8}{|l|}{ PAHs } \\
\hline & Naphthalene & - & - & - & 0.10 & 2.96 & 0.029 \\
\hline & 1-Methylnaphthalene, & - & - & - & 0.59 & 1.10 & 2.06 \\
\hline & 2-Methylnaphthalene, & - & - & 0.12 & 0.82 & 0.48 & 2.86 \\
\hline & 2-Ethenylnaphthalene, & - & - & - & 0.056 & 0.38 & 2.22 \\
\hline & 1,3-Dimethylnaphthalene, & - & - & - & 0.60 & 0.39 & 0.94 \\
\hline & 1,4-Dihydronaphthalene & - & - & 0.81 & 1.18 & 2.19 & - \\
\hline & 1,4-Dihydro-1,4-methanonaphthalene & - & - & - & 0.22 & 0.304 & 0.54 \\
\hline & 1-Isopropenylnaphthalene & - & - & - & - & 0.016 & 0.40 \\
\hline & Sum & 0 & 0 & 0.93 & 3.57 & 7.82 & 9.05 \\
\hline \multirow{2}{*}{ Alcohols } & 1-Hexadecanol & - & - & 3.67 & 5.06 & 3.71 & 0.16 \\
\hline & Sum & 0 & 0 & 3.67 & 5.06 & 3.71 & 0.16 \\
\hline \multirow{4}{*}{ Furans } & 1-(2-Furanyl)ethanone & 0.12 & 0.13 & 0.14 & 0.11 & - & - \\
\hline & Dihydro-3-methylene-2(3H)-furanone & - & - & - & - & 0.12 & 0.0834 \\
\hline & 5-Methyl-2-furancarboxaldehyde & 0.38 & 0.16 & 0.14 & - & - & - \\
\hline & Sum & 0.5 & 0.29 & 0.28 & 0.11 & 0.12 & 0.083 \\
\hline
\end{tabular}


Figure 3. Total ion current diagram of Schizochytrium limacinum pyrolyzed bio-oil at $450{ }^{\circ} \mathrm{C}$.

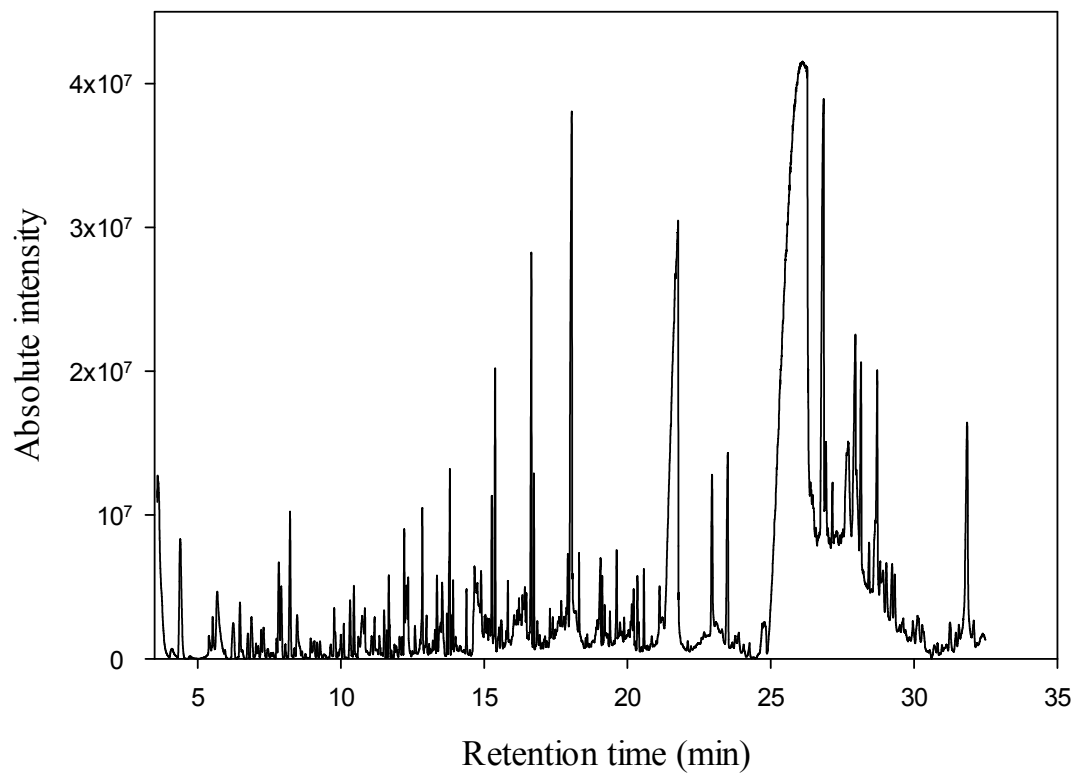

\section{Experimental Section}

\subsection{Sample Preparation}

The Schizochytrium limacinum sample was purchased from Wudi Bioengineering Co., Ltd. (Shandong, China) and preserved at $4{ }^{\circ} \mathrm{C}$ in sealed plastic bags. Major chemical constituents in the Schizochytrium limacinum sample were analyzed by using an elemental analyzer (Flash EA-1112, Thermo Fisher Scientific, Waltham, MA, USA) at the Institute of Chemistry, Chinese Academy of Sciences (Beijing, China). Reported values are an average of at least triplicate experimental runs.

\subsection{Thermal Analysis of Schizochytrium Limacinum}

A thermogravimetric analyzer (TGA) is capable of monitoring even minute variations in weight caused by water evaporation and degradations of compounds [35]. The mass loss as a function of temperature rise of Schizochytrium limacinum was measured using a thermogravimetric analyzer (SDT-Q600, TA Instruments, New Castle, DE, USA) in order to determine its decomposition behavior. Weight calibration of the analyzer was conducted according to the TA Instruments operation manual [36]. Zero point weight of the analyzer was adjusted by placing two empty ceramic sample pans on the thermobalance beams before experiment. Approximately $2 \sim 4 \mathrm{mg}$ of Schizochytrium limacinum was placed into alumina oxide pan and the entire pan and sample were loaded into the TGA. The weight of Schizochytrium limacinum was measured automatically and the empty pan was used as the reference. The furnace was purged with nitrogen (99.999\%, Beijing AP BAIF Gases Industry Co., Ltd., Beijing, China) at a rate of $100 \mathrm{~mL} / \mathrm{min}$. The sample was heated from $40{ }^{\circ} \mathrm{C}$ to $1000{ }^{\circ} \mathrm{C}$ at a rate of $25^{\circ} \mathrm{C} / \mathrm{min}$ using a programmable controller.

The transition temperatures, the enthalpy values of these transitions and specific heat capacity of Schizochytrium limacinum were measured using a differential scanning calorimeter (DSC Q10, TA Instruments, New Castle, DE, USA). The Schizochytrium limacinum sample (approximately $5 \sim 6 \mathrm{mg}$ ) 
was sealed in a standard hermetic aluminum pan and sealed with an aluminum lid. An empty hermetic pan with a lid was used as reference during all tests. Pure indium was used for calibration of the DSC due to its fixed melting temperature $\left(156.61{ }^{\circ} \mathrm{C}\right)$ and melting enthalpy $(28.71 \mathrm{~J} / \mathrm{g})$. A cooling system (RCS90, TA Instruments, New Castle, DE, USA) was attached with this DSC in order to rapidly cool the sample to desired sub-zero temperature. All microalgae samples were scanned from $-70{ }^{\circ} \mathrm{C}$ to $295^{\circ} \mathrm{C}$ at a temperature ramping rate of $10{ }^{\circ} \mathrm{C} / \mathrm{min}$. Dry nitrogen gas $(99.99 \%, 0.2 \mathrm{MPa})$ was used for purging and its flow rate was maintained at $50 \mathrm{~mL} / \mathrm{min}$. Five points of heat flow signals were collected each second. The onset temperature $\left(T_{\mathrm{o}}\right)$ of each transition, variation in specific heat capacity and the transition enthalpy were calculated by Universal Analysis 2000 software (Version 4.3 A, TA Instruments-Waters LLC, New Castle, DE, USA) [36].

\subsection{Real-Time Determination on Pyrolysis of Schizochytrium Limacinum}

The real-time chemical composition analysis of Schizochytrium limacinum pyrolysis was determined using a single-shot pyrolyzer (Frontier Labs 3030i, Koriyama, Fukushima, Japan) connected to a GC-MS (Agilent 7890A/5975C, Santa Clara, CA, USA). Samples were injected into the pyrolyzer and burnt at different temperature from $300{ }^{\circ} \mathrm{C}$ to $800{ }^{\circ} \mathrm{C}$ at an interval of $100{ }^{\circ} \mathrm{C}$. This pyrolyzer was equipped with an inert XL mass spectrum detector and a capillary column $(30 \mathrm{~m}$ in length, $0.25 \mu \mathrm{m}$ internal diameter, HP-5 MS, HP19091s-433, Agilent, Santa Clara, CA, USA). The temperature program in those testes involved holding at $40{ }^{\circ} \mathrm{C}$ for $5 \mathrm{~min}$, ramping the temperature to $200{ }^{\circ} \mathrm{C}$ at a rate of $10{ }^{\circ} \mathrm{C} / \mathrm{min}$, holding at this temperature for $5 \mathrm{~min}$; and finally heating the sample to $250{ }^{\circ} \mathrm{C}$ at a rate of $20^{\circ} \mathrm{C} / \mathrm{min}$ and holding the sample at this temperature for $5 \mathrm{~min}$. The total ion current (TIC) diagrams of Schizochytrium limacinum pyrolysis products were obtained at various temperatures. Results were analyzed using Agilent MSD Productivity Chem Station for GC and GC/MS System Data Analysis application software (Version D 03.00.552, Agilent, Santa Clara, CA, USA). Retention time and the peak area percentage of each compound in the pyrolysis products were determined by comparing with NIST 2011 Database (Version 2.0, National Institute of Standards and Technology, Gaithersburg, MD, USA). The concentration of each compound was calculated from the calibrated area under the peak.

\section{Conclusions}

The main decomposition temperature of Schizochytrium limacinum was $428.16{ }^{\circ} \mathrm{C}$, at which up to $66.5 \%$ of the mass was lost. A further $18.7 \%$ mass loss occurred in a relatively slow pace until $760.17{ }^{\circ} \mathrm{C}$ due to complete decomposition of Schizochytrium limacinum. The pyrolysis of Schizochytrium limacinum at $700{ }^{\circ} \mathrm{C}$ produced a maximum yield (67.7\%) of pyrolysis products compared to $61.2 \%$ at $400{ }^{\circ} \mathrm{C}$. On the other hand, pollutants released at $700{ }^{\circ} \mathrm{C}$ were $12.3 \%$, which were much higher than those of $400{ }^{\circ} \mathrm{C}(2.1 \%)$. Results indicated that excessively high temperature during pyrolysis processing increases the percentage of nitrogen compounds and PAHs. Hence, application of moderate pyrolysis temperature $\left(400{ }^{\circ} \mathrm{C}\right.$ in this paper) is suitable in producing bio-oil from Schizochytrium limacinum in terms of optimal quality and yield. 


\section{Acknowledgments}

This investigation was financially supported by the Chinese National "Twelfth Five-Year" Plan for Science and Technology Supporting Program (Grant No. 2012BAD47B03), The Chinese National Advanced Technology Development Program (Grant No. 2013AA065802), the Second Class General Financial Grant from the China Postdoctoral Science Foundation (Grant No. 2011M500451), 2012 Key Foreign Expert Program of Chinese State Administration of Foreign Experts Affairs (Grant No. 2012z025), and Beijing Municipal Key Discipline of Biomass Engineering. The authors would also like to acknowledge the assistance of the Beijing technical center of TA Instruments for providing some technical support and TGA measurements.

\section{Conflict of Interest}

State any potential conflicts of interest here or "The authors declare no conflict of interest".

\section{References}

1. Demirbas, A.; Demirbas, M.F. Energy from Algae. In Algae Energy: Algae as a New Source of Biodiesel; Demirbas, A., Demirbas, M.F., Eds.; Springer-Verlag London Limited: London, UK, 2010; pp. 97-138.

2. Demirbas, A. Biomass resource facilities and biomass conversion processing for fuels and chemicals. Energy Convers. Manag. 2001, 42, 1357-1378.

3. Li, R.; Zhong, Z.; Jin, B.; Zheng, A. Selection of temperature for bio-oil production from pyrolysis of algae from lake blooms. Energy Fuel 2012, 26, 2996-3002.

4. Du, Z.Y.; Hu, B.; Ma, X.C.; Cheng, Y.L.; Liu, Y.H.; Lin, X.Y.; Wan, Y.Q.; Lei, H.W.; Chen, P.; Ruan, R. Catalytic pyrolysis of microalgae and their three major components: Carbohydrates, proteins, and lipids. Bioresour. Tech. 2013, 130, 777-782.

5. Hu, Z.Q.; Zheng, Y.; Yan, F.; Xiao, B.; Liu, S.M. Bio-oil production through pyrolysis of blue-green algae blooms (BGAB): Product distribution and bio-oil characterization. Energy 2013, 52, 119-125.

6. Greenhalf, C.E.; Nowakowski, D.J.; Harms, A.B.; Titiloye, J.O.; Bridgwater, A.V. A comparative study of straw, perennial grasses and hardwoods in terms of fast pyrolysis products. Fuel 2013, 108, 216-230.

7. Mohan, D.; Pittman, C.U.; Steele, P.H. Pyrolysis of wood/biomass for bio-oil: A critical review. Energy Fuels 2006, 20, 848-889.

8. Cantrell, K.B.; Ducey, T.; Ro, K.S.; Hunt, P.G. Livestock waste-to-bioenergy generation opportunities. Bioresour. Tech. 2008, 99, 7941-7953.

9. Goyal, H.B.; Seal, D.; Saxena, R.C. Bio-fuels from thermochemical conversion of renewable resources: A review. Renew. Sustain. Energy Rev. 2008, 12, 504-517.

10. Miao, X.; Wu, Q. High yield bio-oil production from fast pyrolysis by metabolic controlling of Chlorella protothecoides. J. Biotech. 2004, 110, 85-93.

11. Miao, X.; Wu, Q.; Yang, C. Fast pyrolysis of microalgae to produce renewable fuels. J. Anal. Appl. Pyrolysis 2004, 71, 855-863. 
12. Hu, Z.; Ma, X.; Chen, C. A study on experimental characteristic of microwave-assisted pyrolysis of microalgae. Bioresour. Tech. 2011, 107, 487-493.

13. Bassilakis, R.; Carangelo, R.M.; Wójtowicz, M.A. TG-FTIR analysis of biomass pyrolysis. Fuel 2001, 80, 1765-1786.

14. De Jong, W.; Pirone, A.; Wójtowicz, M.A. Pyrolysis of Miscanthus Giganteus and wood pellets: TG-FTIR analysis and reaction kinetics. Fuel 2003, 82, 1139-1147.

15. Jensen, A.; Dam-Johansen, K.; Wójtowicz, M.A.; Serio, M.A. TG-FTIR study of the influence of potassium chloride on wheat straw pyrolysis. Energy Fuel 1998, 12, 929-938.

16. Liu, Q.; Wang, S.; Zheng, Y.; Luo, Z.; Cen, K. Mechanism study of wood lignin pyrolysis by using TG-FTIR analysis. J. Anal. Appl. Pyrolysis 2008, 82, 170-177.

17. Andreotti, A.; Bonaduce, I.; Colombini, M.P.; Gautier, G.; Modugno, F.; Ribechini, E. Combined GC/MS analytical procedure for the characterization of glycerolipid, waxy, resinous, and proteinaceous materials in a unique paint microsample. Anal. Chem. 2006, 78, 4490-4500.

18. Branca, C.; Giudicianni, P.; Blasi, C.D. GC/MS characterization of liquids generated from low-temperature pyrolysis of wood. Ind. Eng. Chem. Res. 2003, 42, 3190-3202.

19. Colombini, M.P.; Modugno, F.; Giannarelli, S.; Fuoco, R.; Matteini, M. GC-MS characterization of paint varnishes. Microchem. J. 2000, 67, 385-396.

20. Potter, D.W.; Pawliszyn, J. Rapid determination of polyaromatic hydrocarbons and polychlorinated biphenyls in water using solid-phase microextraction and GC/MS. Environ. Sci. Tech. 1994, 28, 298-305.

21. Thangalazhy-Gopakumar, S.; Adhikari, S.; Gupta, R.B. Catalytic pyrolysis of biomass over $\mathrm{H}^{+}$ZSM-5 under hydrogen pressure. Energy Fuels 2012, 26, 5300-5306.

22. Li, X.H.; Meng, Y.Z.; Zhu, Q.; Tjong, S.C. Thermal decomposition characteristics of poly (propylene carbonate) using TG/IR and Py-GC/MS techniques. Polym. Degrad. Stab. 2003, 81, 157-165.

23. Ralph, J.; Hatfield, R.D. Pyrolysis-GC-MS characterization of forage materials. J. Agric. Food Chem. 1991, 39, 1426-1437.

24. Ross, A.B.; Anastasakis, K.; Kubacki, M.; Jones, J.M. Investigation of the pyrolysis behaviour of brown algae before and after pre-treatment using PY-GC/MS and TGA. J. Anal. Appl. Pyrolysis 2009, 85, 3-10.

25. Scholze, B.; Meier, D. Characterization of the water-insoluble fraction from pyrolysis oil (pyrolytic lignin): Part I. Py-GC/MS, FTIR, and functional groups. J. Anal. Appl. Pyrolysis 2001, 60, 41-54.

26. Bae, Y.J.; Ryu, C.; Jeon, J.K.; Park, J.; Suh, D.J.; Suh, Y.W. The characteristics of bio-oil produced from the pyrolysis of three marine macroalgae. Bioresour. Tech. 2011, 102, 3512-3520.

27. Relkin, P. Using thermal analysis and combined techniques for food characterization (Report on panel presentation). J. Therm. Anal. Calor. 2005, 80, 799-801.

28. Ross, A.B.; Jones, J.M.; Kubacki, M.L.; Brideman, T. Classification of macroalgae as fuel and its thermochemical behavior. Bioresour. Tech. 2008, 99, 6494-6504. 
29. Thangalazhy-Gopakumar, S.; Adhikari, S.; Chattanathan, S.A.; Gupta, R.B. Catalytic pyrolysis of green algae for hydrocarbon production using $\mathrm{H}^{+} \mathrm{ZSM}-5$ catalyst. Bioresour. Tech. 2012, 118 , $150-157$.

30. Du, Z.; Li, Y.; Wang, X.; Wan, Y.; Chen, Q.; Wang, C.; Lin, X.; Liu, Y.; Chen, P.; Ruan, R. Microwave-assisted pyrolysis of microalgae for biofuel production. Bioresour. Tech. 2011, 102, 4890-4896.

31. Adam, J.; Antonakou, E.; Lappas, A.; Stöcker, M.; Nilsen, M.H.; Bouzga, A.; Hustad, J.E.; Øye, G. In situ catalytic upgrading of biomass derived fast pyrolysis vapours in a fixed bed reactor using mesoporous materials. Microporous Mesoporous Mater. 2006, 96, 93-101.

32. Wang, X.H.; Chen, H.P.; Ding, X.J.; Yang, H.P.; Zhang, S.H.; Shen, Y.Q. Properties of gas and char from microwave pyrolysis of pine sawdust. Bioresour. Tech. 2009, 4, 946-959.

33. Zhang, H.; Xiao, R.; Huang, H.; Xiao, G. Comparison of non-catalytic and catalytic fast pyrolysis of corncob in a fluidized bed reactor. Bioresour. Tech. 2009, 100, 1428-1434.

34. Maddi, B.; Viamajala, S.; Varanasi, S. Comparative study of pyrolysis of algal biomass from natural lake blooms with lignocellulosic biomass. Bioresour. Tech. 2011, 102, 11018-11026.

35. Castelli, F.; Gilbert, S.M.; Caruso, S.; Maccarrone, D.E.; Fisichella, S. Thermoanalytical characterization of high molecular weight glutenin subunits water effect on their glass transition. Thermochimica. Acta. 2000, 346, 153-160.

36. TA Instruments. Simultaneous DSC-TGA Getting Started Guide; TA Instruments-Waters LLC: New Castle, DE, USA, 2004.

(C) 2013 by the authors; licensee MDPI, Basel, Switzerland. This article is an open access article distributed under the terms and conditions of the Creative Commons Attribution license (http://creativecommons.org/licenses/by/3.0/). 